\title{
SUCESSÕES DE CULTURAS COM PLANTAS DE COBERTURA E MILHO EM PLANTIO DIRETO E SUA INFLUÊ NCIA SOBRE O NITROGÊNIO NO SOLO(1)
}

\author{
C. N. GONÇALVES ${ }^{(2)}$, C. A. CERETTA ${ }^{(3)} \&$ C. J . BASSO ${ }^{(4)}$
}

\begin{abstract}
RESUMO
Em condições naturais, o solo encontra-se em equilíbrio, mas o manejo inadequado causa degradação, principalmente da fração orgânica, comprometendo a sustentabilidade de sistemas agrícolas. Este trabalho, realizado num experimento de seis anos em Argissolo Vermelho-Amarelo (Hapludalf), localizado na área experimental do Departamento de Solos da Universidade Federal de Santa Maria (RS), teve como objetivo avaliar a influência de cinco sucessões de culturas no nitrogênio do solo, sob plantio direto. Foram implantadas as sucessões de culturas ervilhaca comum (Vicia sativa)/milho (Zea mays), tremoço azul (Lupi nus angusti folius)/milho, ervilha forrageira (Pisum arvense)/ milho, aveia-preta (Avena strigosa)/milho e pousio/milho, associadas a duas doses de $\mathrm{N}$ aplicadas no milho ( 0 e $80 \mathrm{~kg} \mathrm{ha}^{-1}$ ). $\mathrm{O}$ solo foi manejado em plantio direto e foram feitas avaliações dos teores de $\mathbf{N}$ das plantas de cobertura e dos resíduos vegetais superficiais, bem como do ni trogênio do solo (total, mineral e orgânico), em três profundidades (0-2,5; 2,5-7,5 e 7,5-17,5 cm). As avaliações das plantas de cobertura de solo no inverno foram realizadas nas subparcelas sem aplicação de $\mathbf{N}$ mineral. Os resultados mostraram que a introdução de plantas de cobertura de solo, sob plantio direto, durante seis anos, promoveu acúmulos significativos de nitrogênio mineral, orgânico e total no solo e apresentaram diferenças entre as sucessões de culturas, apenas na camada de $0-2,5 \mathrm{~cm}$. A sucessão tremoço azul/mi lho destacou-se pela capacidade de promover acréscimos de nitrogênio no solo.
\end{abstract}

Termos de indexação: fitomassa, seqüência de culturas, melhoramento do solo.

(1) Parte da Tese de Mestrado submetida, pelo primeiro autor à Universidade Federal de Santa Maria para obtenção do título de Mestre em Agronomia. Recebido para publicação em fevereiro de 1999 e aprovado em dezembro de 1999.

(2) Engenheiro-Agrônomo, Doutorando em Ciência do Solo, Universidade Federal do Rio Grande do Sul, E-mail: cristianong@zipmail.com.br

(3) Engenheiro-Agrônomo, Professor Titular do Departamento de Solos, Universidade Federal de Santa Maria, CEP 97105-900 Santa Maria (RS). Bolsista do CNPq. E-mail: ceretta@ccr.ufsm.br

(4) Engenheiro-Agrônomo, Doutorando em Agronomia - Biodinâmica do Solo, Universidade Federal de Santa Maria. 


\title{
SUMMARY: PLANT SUCCESSIONS OF COVER CROPS AND CORN UNDER NO TILLAGE SYSTEM AND THEIR EFFECTS ON SOIL NITROGEN
}

\begin{abstract}
Soil is in a steady stateunder natural conditions, but an inadequatemanagement can causedegradation, mainly of theorganic matter, impairing thesustainability of agricultural systems. The present study was undertaken in a six-year-old field experiment on a typic Hapludalf (Red Yellow Podzolic Soil), at the Department of Soil Science, UFSM, Santa Maria, Rio Grande do Sul state, Brazil, to evaluate the effects of plant successi ons on soil nitrogen dynamics, under no tillagesystem. Theplant successi ons used werecommon vetch (Vicia sativa)/ corn (Zea mays), bluelupine (L upinus angustifol ius)/ corn, field peas (Pisum arvense)/ corn, black oat (Avena strigosa)/ corn and winter fallow/ corn, associated to two nitrogen doses $\left(0\right.$ and $\left.80 \mathrm{~kg} \mathrm{ha}^{-1}\right)$ applied on corn. The soil was managed by the no-tillage system, and evaluations were made on thelevels of $\mathrm{N}$ on the cover crops and on the surface plant residues, and of thesoil nitrogen under total, mineral and organicforms, at threesoil depths $(0-2.5 ; 2.5-7.5$ and $7.5-17.5 \mathrm{~cm})$. The winter cover crop soil evaluati ons weremade in areas without mineral $\mathrm{N}$ fertilizer. The use of soil cover crops, during six years under no tillage, induced significant increase of soil mineral, organic and total nitrogen. The crop succession caused differences only in $0-2.5 \mathrm{~cm}$ layer. The succession lupine/ corn caused higher soil $\mathrm{N}$ improvement.
\end{abstract}

Index terms: dry matter, crop succession, soil improvement.

\section{NTRODUÇÃO}

Em condições naturais, o solo encontra-se em equilíbrio, apresentando uma cobertura vegetal nativa eum balanço entre as taxas de adição e perda de nitrogênio (N) (Sanchez, 1976). O uso do sol o para fins agrícolas rompe esse equilíbrio dinâmico, podendo comprometer os níveis de $\mathrm{N}$ do solo quando há revolvimento, decorrente da diminuição da proteção física da matéria orgânica do solo (Bayer, 1996). Entretanto, com a adoção do sistema plantio direto, após ocorrer o restabelecimento do equilíbrio das transformações no sol o, o bal anço entre adição e perda de $\mathrm{N}$ dosoloémais equilibrado, havendo maior liberação de N às plantas (Sá, 1995).

O N é um dos nutrientes requeridos em maior quantidade pelas plantas. Apesar de existir em grande quantidade na forma de $\mathrm{N}_{2}$-atmosférico, a fonte de $\mathrm{N}$ para as plantas não-simbióticas é o solo. No solo, segundo Bremner (1965) e Fassbender (1975), o nitrogênio encontra-se, em sua mai or parte (85-95\%), sob a forma orgânica e, em pequena proporção (5-15\%), sob a forma mineral $\left(\mathrm{NO}_{3}{ }^{-}, \mathrm{NO}_{2}{ }^{-}\right.$ e $\mathrm{NH}_{4}{ }^{+}$), sendo $\mathrm{O} \mathrm{NO}_{3}{ }^{-}$a forma predominante utilizada pelos vegetais. Com a predominância da forma orgânica de N, sol os com alto teor de matéria orgânica apresentam alto potencial de suprimento de $\mathrm{N}$ para as culturas.

Um fertilizante nitrogenado, quando adicionado ao solo, torna-se rapidamente parte de compostos orgânicos recém-formados no solo (Stanford et al., 1970). Entretanto, Legg et al. (1971), trabalhando com ${ }^{15} \mathrm{~N}$ de fertilizante, notaram que o principal efeito do cultivo contínuo do solo foi o aumento da quantidade deste $\mathrm{N}$ incorporado em formas orgânicas estavéis. Essas observações foram confirmadas por Ceretta (1995), após nove anos em sol o sob sistemas de cultura em plantio direto. Esse autor demonstrou acréscimos de até $92 \%$ na quantidade de $\mathrm{N}$ em ácidos húmicos, considerada uma das frações mais estáveis da matéria orgânica do solo.

A quantidade de $\mathrm{N}$ recuperado pelas plantas depende, entre outros fatores, das características dos resíduos vegetais, do tipo de cultura, das condições ambientais e do tipo de manejo adotado. Das quantidades de $\mathrm{N}$ adicionados ao solo, muito pouco é recuperado pelas plantas, evidenciando a grande perda de $\mathrm{N}$ no solo, em virtude de processos de volatilização, Iixiviação, desnitrificação e erosão (Stevenson, 1982). Em anos com intensas precipitações pluviais, pode ocorrer expressiva perda de $\mathrm{N}$ do solo por lixiviação (Ceretta, 1998). U ma das formas de minimizar esse problema é manter sempre plantas em crescimento para reciclagem de nutrientes e cobertura do solo, mesmo que seja com espécies que não fixam $\mathrm{N}$, mas que acumulam e reciclam grande quantidade de $\mathrm{N}$ na biomassa, evitando sua perda por lixiviação (E bel har et al., 1984).

Caso não haja um equilíbrio entre a quantidade de $\mathrm{N}$ adicionada ao solo e a quantidade perdida anualmente, pode ocorrer uma redução da capacidade do solo em fornecer nitrogênio para as culturas, levando a um declínio progressivo da produtividade do sistema (Dalal \& Mayer, 1986) e comprometendoa manutenção deníveis satisfatórios 
de $\mathrm{N}$ no solo. A adição de $\mathrm{N}$ via fixação de $\mathrm{N}_{2^{-}}$ atmosférico pela utilização de leguminosas melhoraria o balanço de $\mathrm{N}$ no solo de forma mais acel erada (Bayer, 1992).

No plantio direto, o estudo de diferentes sistemas de cultura requer a execução de trabalhos de longa duração, porque seus efeitos são cumulativos. O objetivo desteestudo foi avaliar a influência de cinco sucessões de culturas sobre o nitrogênio do solo no sistema plantio direto.

\section{MATE RIAL E MÉTODOS}

O trabal ho de campo foi desenvolvido de 1990 a 1996, sob plantio direto, em área experimental do Departamento de Sol os da U niversidade F ederal de Santa Maria, Santa Maria (RS), em Argissolo Vermel ho-Amarelo (Hapludalf) pertencente à Unidade de Mapeamento São Pedro (Brasil, 1973), com textura franco-arenosa no horizonte $A$ efrancoargilosa no B. Antes da instalação do trabalho de campo, a área foi cultivada com as sucessões aveia/ soja (1988/89) e ervilhaca + aveia/milho (1989/90), com aplicação de fertilizante mineral nas culturas de verão e calcário no inverno de 1989. Os resultados apresentados e analisados neste trabal ho foram obtidos no ano agrícola 1995/1996, refletindo o efeito das sucessões após seis anos de implantação.

O delineamento experimental foi em blocos casualizados com parcelas subdivididas e quatro repetições. Nas parcelas de $10 \times 5 \mathrm{~m}$, foram testadas cinco plantas de cobertura de solo no inverno: ervilhaca comum (Vicia sativa), tremoço azul (Lupinus angustifolius), ervilha forrageira (Pisum arvense), aveia-preta (Avena strigosa) e pousio invernal, e, nas subparcelas, de $5 \times 5 \mathrm{~m}$, dois níveis de adubação nitrogenada ( 0 e 80 kg ha-1 de $\mathrm{N}$ na forma de uréia, em cobertura), aplicados no milho cultivado em sucessão.

O milho híbrido Braskal b XL-250 foi semeado no espaçamento de um metro entre as linhas e seis sementes por metro, obtendo-se uma população final de cerca de 50.000 plantas ha-1.

A adubação com fósforo e potássio no milho foi uniforme em todos os tratamentos. Utilizaram-se $44 \mathrm{~kg} \mathrm{ha}^{-1}$ de $\mathrm{P}_{2} \mathrm{O}_{5}$ e $58 \mathrm{~kg} \mathrm{ha}^{-1}$ de $\mathrm{K}_{2} \mathrm{O}$, aplicados a Ianço, como superfosfato triplo ecl oreto de potássio.

A adubação nitrogenada no milho foi realizada na semeadura e em cobertura, aos 21 e 30 dias da emergência. Nas duas primeiras aplicações, foram distribuídos $25 \mathrm{~kg} \mathrm{ha}^{-1}$ e, na terceira, $30 \mathrm{~kg} \mathrm{ha}^{-1}$ de nitrogênio, utilizando-se uréia. As adubações de cobertura for am sem incorporação ao solo, tendo sido realizada irrigação por aspersão após sua aplicação.
No início do trabalho, em 1990, o solo apresentou as seguintes características na profundidade de 0-20 cm: $150 \mathrm{~g} \mathrm{~kg}^{-1}$ deargila $(\mathrm{m} / \mathrm{N}) ; \mathrm{pH}^{\mathrm{em} \mathrm{H}} \mathrm{O}_{2} \mathrm{O}(1: 1)$,

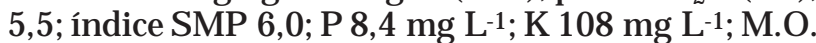
$7,5 \mathrm{~g} \mathrm{~kg}^{-1}(\mathrm{~m} / \mathrm{N}) ; \mathrm{Ca}^{2+}+\mathrm{Mg}^{2}+1,6 \mathrm{cmol}_{\mathrm{C}} \mathrm{L}^{-1}$ e $\mathrm{Al}^{3+}$ $0,12 \mathrm{cmol}_{\mathrm{C}} \mathrm{L}^{-1}$ (Da Ros, 1993) e densidade de $1,64 \mathrm{~kg} \mathrm{dm}^{-3}$.

Nos tratamentos anteriores ao estabelecimento das culturas de cobertura de solo no inverno, no tratamento em pousio, as invasoras foram dessecadas com aplicação de herbicida à base de glyphosate, sendo, posteriormente, as culturas de cobertura semeadas a lanço e sem adubação. No manejo das plantas de cobertura de sol o no inverno, foi utilizada roçadeira motorizada manual.

A col eta deamostras, numa área de 0,64 m², para avaliar a produção de fitomassa da parte aérea, foi efetuada a partir de três subamostras em outubro de 1995, quando todas as espécies haviam ultrapassado a fase de pleno florescimento. Foram feitas amostragens nas subparcel as onde o mil ho foi cultivado em sucessão, sem aplicação de adubação nitrogenada mineral. A col eta dos resíduos culturais foi efetuada também em outubro de 1995, em duas subamostras de $0,10 \mathrm{~m}^{2}$ por subparcela, em todas as subparcelas. As amostras foram secas em estufa a $65^{\circ} \mathrm{C}$ até peso constante. Considerou-se como resíduo cultural o material orgânico acumulado na superfície do solo ao longo de seis anos.

As amostras de solo foram retiradas antes da semeadura do milho em outubro de 1995 e obtidas de duas subamostras em cada subparcela. A amostragem foi realizada em três profundidades no perfil do solo: $0-2,5 \mathrm{~cm}$ - todo o volume contido na área de $20 \times 20 \mathrm{~cm} ; 2,5-7,5 \mathrm{~cm}$ - todo ovolumecontido na área de $20 \times 15 \mathrm{~cm} ; 7,5-17,5 \mathrm{~cm}$ - todo o volume contidona área de $20 \times 10 \mathrm{~cm}$. O local deamostragem de sol ofoi o mesmo utilizado para col eta deresíduos culturais. As subamostras foram secas ao ar e à sombra, misturadas, homogeneizadas, moídas e tamisadas em malha de 2,00 mm.

Foram determinados os teores de nitrogênio total e nitrogênio mineral do solo pelos métodos de Kjeldahl, de Bremner e Keeney, respectivamente, descritos por Tedesco et al . (1995). As determinações de nitrogênio das plantas de cobertura de inverno e dos resíduos culturais foram realizadas de acordo com o método descrito por Tedesco et al. (1995).

A análise estatística dos dados constou da análise de variância, com aplicação do teste $F$ e, para as fontes onde ocorreram diferenças significativas, utilizou-se o teste de Duncan a $5 \%$ para a comparação de médias, bem como a regressão simples e a correlação para correlacionar dados. O pacote estatístico SAS foi utilizado para realizar a análise de variância e o teste F. 


\section{RESULTADOS E DISCUSSÃO}

A produção de matéria seca e o teor e quantidade de nitrogênio variaram entre as diferentes plantas de cobertura de solo no inverno (Quadro 1). O tremoço azul destacou-se tanto na produção de massa quanto na quantidade de $\mathrm{N}$ adicionado ao solo; sua presença, antecedendo ao milho, também se sobressaiu quanto à capacidade de promover acúmulo de carbono no solo, conforme mostram Gonçalves \& Ceretta (1999).

O sucesso do plantio direto depende da produção de fitomassa para proteção do solo, especialmente contra a erosão. E sse aspecto e outros apresentados por Ceretta (1998) justificam a predominância da aveia preta como planta de cobertura de solo no inverno; neste trabalho, el a foi capaz de proporcionar acréscimo de $79 \%$ na quanti dade demassa produzida no inverno, comparado com a área mantida em pousio. Isso é particularmente importante no Rio Grande do Sul, onde, até o início da década de 90, Pavinato et al. (1994) ressaltavam que dois terços da área cultivada noverão permaneciam descobertos no inverno e sujeitos à ação dos agentes erosivos.

Tanto quanto a produção de fitomassa a sua manutenção sobre o solo o maior tempo possível também é importanteno plantio direto. Os resíduos vegetais localizados na superfície do solo são constituídos de restos de culturas remanescentes de cultivos anteriores (Bayer, 1992), e sua quantidade sobre o sol o pode ser considerada como uma síntese das adi ções e perdas ocorridas (Pavinato, 1993), após seis anos de realização deste trabal ho. As sucessões tremoço azul/milho e ervilhaca comum/milho destacaram-se quanto à quantidade de resíduos vegetais acumulados na superfície do solo, apesar de não diferirem estatisticamente das sucessões ervilha forrageira/milho e pousio/milho (Quadro 2).

Quadro 1. Produção de matéria seca, teor e quantidade total de nitrogênio na parte aérea de plantas de cobertura de solo no inverno

\begin{tabular}{|c|c|c|c|c|c|}
\hline $\begin{array}{l}\text { Planta de cobertura } \\
\text { de solo no inverno }\end{array}$ & $\begin{array}{l}\text { Matéria } \\
\text { seca }\end{array}$ & $\begin{array}{l}\text { Valor } \\
\text { relativo }\end{array}$ & $\begin{array}{c}\text { Teor de } \\
\text { nitrogênio }\end{array}$ & $\begin{array}{l}\text { Quantidade de } \\
\text { nitrogênio }\end{array}$ & $\begin{array}{l}\text { Valor } \\
\text { relativo }\end{array}$ \\
\hline & $\mathrm{Mg} \mathrm{ha}^{-1}$ & $\%$ & $\mathrm{~g} \mathrm{~kg}^{-1}$ & $\mathrm{~kg} \mathrm{ha}^{-1}$ & $\%$ \\
\hline $\begin{array}{l}\text { Ervilhaca comum } \\
\text { Tremoço azul } \\
\text { Ervilha forrageira } \\
\text { Aveia preta } \\
\text { Pousio }\end{array}$ & $\begin{array}{l}2,98 \mathrm{~b}^{(1)} \\
5,02 \mathrm{a} \\
1,59 \mathrm{c} \\
3,29 \mathrm{~b} \\
1,84 \mathrm{c}\end{array}$ & $\begin{array}{r}162 \\
273 \\
86 \\
179 \\
100\end{array}$ & $\begin{array}{r}21,6 \mathrm{a} \\
21,2 \mathrm{a} \\
17,9 \mathrm{~b} \\
9,9 \mathrm{~d} \\
14,5 \mathrm{c}\end{array}$ & $\begin{array}{r}64,6 \mathrm{~b} \\
106,5 \mathrm{a} \\
28,5 \mathrm{c} \\
32,5 \mathrm{c} \\
26,6 \mathrm{c}\end{array}$ & $\begin{array}{l}242 \\
400 \\
107 \\
122 \\
100\end{array}$ \\
\hline C.V. (\%) & 21,41 & & 9,77 & 23,24 & \\
\hline
\end{tabular}

Médias seguidas da mesma letra, na mesma coluna, não diferem significativamente entre si, pelo teste de Duncan a 5\%.

(1) Média proveniente de quatro repetições.

Quadro 2. Quantidade de matéria seca, teor e quantidade total de nitrogênio nos resíduos vegetais mantidos na superfície do solo em cinco sucessões de culturas

\begin{tabular}{|c|c|c|c|c|c|}
\hline $\begin{array}{l}\text { Sucessão } \\
\text { de cultura }\end{array}$ & $\begin{array}{l}\text { Matéria } \\
\text { seca }\end{array}$ & $\begin{array}{l}\text { Valor } \\
\text { relativo }\end{array}$ & $\begin{array}{c}\text { Teor de } \\
\text { nitrogênio }\end{array}$ & $\begin{array}{c}\text { Quantidade de } \mathbf{N} \\
\text { acumulado }\end{array}$ & $\begin{array}{l}\text { Valor } \\
\text { relativo }\end{array}$ \\
\hline & $\mathrm{Mg} \mathrm{ha}^{-1}$ & $\%$ & $\mathrm{~g} \mathrm{~kg}^{-1}$ & kg ha-1 & $\%$ \\
\hline $\begin{array}{l}\text { Ervilhaca comum/milho } \\
\text { Tremoço azul/milho } \\
\text { Ervilha forrageira/milho } \\
\text { Aveia preta/milho } \\
\text { Pousio/milho(3) }\end{array}$ & $\begin{array}{l}6,40 a b^{(1)} \\
7,38 a \\
5,64 a b \\
4,30 \mathrm{~b} \\
5,41 \mathrm{ab}\end{array}$ & $\begin{array}{r}118 \\
136 \\
104 \\
80 \\
100\end{array}$ & $\begin{array}{c}13,5 \mathrm{a} \\
11,4 \mathrm{~b} \\
9,7 \mathrm{bc} \\
9,3 \mathrm{c} \\
9,6 \mathrm{c}\end{array}$ & $\begin{array}{l}86,6 \mathrm{a} \\
84,3 \mathrm{a} \\
54,7 \mathrm{~b} \\
40,2 \mathrm{~b} \\
51,6 \mathrm{~b}\end{array}$ & $\begin{array}{r}168 \\
163 \\
106 \\
78 \\
100\end{array}$ \\
\hline C.V. (\%) & 34,92 & & 16,21 & 38,45 & \\
\hline
\end{tabular}

Não houve interação entre dose de $\mathrm{N}$ aplicada no milho e sistema de cultura, optando-se, a partir disto, em efetuar a comparação entre as sucessões, considerando a média de quatro repetições onde o milho foi cultivado sem aplicação de $\mathrm{N}$ e quatro repetições onde foi aplicado $80 \mathrm{~kg} \mathrm{ha}^{-1}$ de $\mathrm{N}$ no milho. Por isso, as médias são provenientes de oito repetições.

(1) Médias seguidas da mesma letra, na mesma coluna, não diferem significativamente entre si, pelo teste de Duncan a 5\%. 
Foi sobre os sistemas tremoço azul/milho e ervilhaca comum/milho que se observou maior quantidade de nitrogênio nos resíduos vegetais acumulados sobre a superfície do solo. A quantidade de nitrogênio nos resíduos superficiais variou com as características das plantas que compõem as sucessões de cultura. Nessas duas sucessões, tremoço azul/milho e ervilhaca comum/milho, a produção de matéria seca e a quantidade de $\mathrm{N}$ presente nos resíduos superficiais foram 27 e $66 \%$ superiores aos valores obtidos no pousio, respectivamente. Isso se deve ao favorecimento do crescimento de plantas de milho cultivadas sobre resíduos de leguminosas e cujos resíduos somaram-se ao longo do tempo com aqueles provenientes das plantas de cobertura de solo. Por outrolado, na sucessão aveia preta/milho, a quantidade de matéria seca de resíduos vegetais na superfície do sol o foi inferior à do tremoço azul e similar às demais sucessões. $O$ fato de a aveia preta apresentar alta produção dematéria seca no inverno (Quadro 1), mas apresentar-se entre aquelas com menores quantidades de resíduos acumulados sobre a superfície do solo (Quadro 2), evidencia que, quando o milho é cultivado em sucessão à aveia, a contribuição de matéria seca do milho para o acúmul o de resíduos vegetais na superfície do sol oé inferior. I sso pode ser explicado pela alta relação C/ $\mathrm{N}$ na matéria seca da aveia (48), imobilizando $\mathrm{N}$ do sol o e comprometendo a disponibilidade de $\mathrm{N}$ para o milho cultivado em sucessão, causando redução na produção de matéria seca do milho.

Com relaçãoao $\mathrm{N}$ do sol o, observa-se, no quadro 3, que todas as formas de $\mathrm{N}$ apresentaram diferença entre as sucessões apenas na profundidade de 0$2,5 \mathrm{~cm}$. Nessa profundidade, na sucessão pousio/ milho registraram-se os menores teores de nitrogênio total (NT) e nitrogênio orgânico (NO), não sendo estas diferenças significativas em relação à sucessão ervil ha forrageira/milho. Para o nitrogênio mineral (NM), estas diferenças também não foram significativas em relação à sucessão aveia preta/ milho.

Na sucessão ervilha forrageira/milho, ocorreram os menores teores de NT e NO na profundidade de $0-17,5 \mathrm{~cm}$, os quais não diferiram significativamente das sucessões ervilhaca comum/milho e pousio/ milho. Observou-se que o cultivo todos os anos de mesma espécie de plantas de cobertura na mesma área prejudicou o crescimento das plantas. Isso foi

Quadro 3. E feito de sucessões de cultura sobre os teores de nitrogênio total, nitrogênio mineral e nitrogênio orgânico em três profundidades de um solo Podzólico Vermelho-Amarelo

\begin{tabular}{|c|c|c|c|c|c|}
\hline \multirow{2}{*}{$\begin{array}{l}\text { Sucessão } \\
\text { de cultura }\end{array}$} & \multicolumn{3}{|c|}{ Profundidade do solo $(\mathrm{cm})$} & \multirow{2}{*}{\multicolumn{2}{|c|}{$\frac{\text { Média ponderada }}{0-17,5 \mathrm{~cm}^{(1)}}$}} \\
\hline & $0-2,5$ & $2,5-7,5$ & 7,5-17,5 & & \\
\hline & \multicolumn{4}{|c|}{ Nitrogênio total (mg kg-1) } & $\%(2)$ \\
\hline $\begin{array}{l}\text { Ervilhaca comum/M } \\
\text { Tremoço azul/M } \\
\text { Ervilha forrageira/M } \\
\text { Aveia preta/M } \\
\text { Pousio/M (5) }\end{array}$ & $\begin{array}{l}509 \mathrm{Aa}^{(3)} \\
498 \mathrm{Aa} \\
416 \mathrm{Abc} \\
488 \mathrm{Aab} \\
390 \mathrm{AC}\end{array}$ & $\begin{array}{l}291 \mathrm{Ba} \\
343 \mathrm{Ba} \\
307 \mathrm{Ba} \\
304 \mathrm{Ba} \\
274 \mathrm{Ba}\end{array}$ & $\begin{array}{l}234 \mathrm{Ca} \\
251 \mathrm{Ca} \\
212 \mathrm{Ca} \\
251 \mathrm{Ca} \\
244 \mathrm{Ba}\end{array}$ & $\begin{array}{l}289 \mathrm{bc} \\
317 \mathrm{a} \\
268 \mathrm{c} \\
300 \mathrm{ab} \\
273 \mathrm{bc}\end{array}$ & $\begin{array}{r}106 \\
116 \\
98 \\
110 \\
100\end{array}$ \\
\hline & \multicolumn{5}{|c|}{ Nitrogênio mineral (mg kg-1) } \\
\hline $\begin{array}{l}\text { Ervilhaca comum/M } \\
\text { Tremoço azul/M } \\
\text { Ervilha forrageira/M } \\
\text { Aveia preta/M } \\
\text { Pousio/M }\end{array}$ & $\begin{array}{l}33 \mathrm{Aa} \\
31 \mathrm{Aa} \\
18 \mathrm{Ab} \\
22 \mathrm{Ab} \\
20 \mathrm{Ab}\end{array}$ & $\begin{array}{r}13 \mathrm{Ba} \\
12 \mathrm{Ba} \\
10 \mathrm{Ba} \\
10 \mathrm{Ba} \\
9 \mathrm{Ba}\end{array}$ & $\begin{array}{l}7 \mathrm{Ca} \\
7 \mathrm{Ba} \\
8 \mathrm{Ba} \\
7 \mathrm{Ba} \\
8 \mathrm{Ba}\end{array}$ & $\begin{array}{r}13 \mathrm{a} \\
12 \mathrm{a} \\
9 \mathrm{~b} \\
10 \mathrm{~b} \\
10 \mathrm{~b}\end{array}$ & $\begin{array}{r}125 \\
122 \\
97 \\
101 \\
100\end{array}$ \\
\hline Pousio/M & \multicolumn{5}{|c|}{ Nitrogênio orgânico (mg kg-1) } \\
\hline $\begin{array}{l}\text { Ervilhaca comum/M } \\
\text { Tremoço azul/M } \\
\text { Ervilha forrageira/M } \\
\text { Aveia preta/M } \\
\text { Pousio/M }\end{array}$ & $\begin{array}{l}476 \mathrm{Aa} \\
467 \mathrm{Aa} \\
399 \mathrm{Aab} \\
467 \mathrm{Aa} \\
370 \mathrm{Ab}\end{array}$ & $\begin{array}{l}278 \mathrm{Ba} \\
331 \mathrm{Ba} \\
298 \mathrm{Ba} \\
294 \mathrm{Ba} \\
265 \mathrm{Ba}\end{array}$ & $\begin{array}{l}227 \mathrm{Ba} \\
243 \mathrm{Ca} \\
204 \mathrm{Ca} \\
243 \mathrm{Ba} \\
235 \mathrm{Ba}\end{array}$ & $\begin{array}{l}277 \mathrm{bc} \\
305 \mathrm{a} \\
258 \mathrm{c} \\
290 \mathrm{ab} \\
263 \mathrm{bc}\end{array}$ & $\begin{array}{r}105 \\
116 \\
98 \\
110 \\
100\end{array}$ \\
\hline
\end{tabular}

Os coeficientes de variação foram de 16, 20, 33, 38 e 16,55\%, respectivamente, para nitrogênio total, nitrogênio mineral e nitrogê nio orgânico. Não houve interação entre dose de N aplicada no milho e sistema de cultura, optando-se, a partir disto, em efetuar a comparação entre as sucessões, considerando a média de quatro repetições sem aplicação de $\mathrm{N}$ no milho e quatro repetições com aplicação de $80 \mathrm{~kg} \mathrm{ha}^{-1}$ de N no milho.

(1) (Média 0-2,5 . 2,5) + (Média 2,5-7,5 . 5,0) + (Média 7,5-17,5 . 10) 17,5

(2) Percentagem em relação ao pousio na profundidade $0-17,5 \mathrm{~cm}$. (3) Médias provenientes de oito repetições. Médias seguidas da mesma letra maiúscula na linha e minúscula na coluna não diferem significativamente entre si pelo teste de Duncan a $5 \%$. 
percebido especial mente no caso do cultivo de ervilha forrageira, onde houve redução de $60 \%$ na produção de matéria seca, desde a instalação da cultura em 1990 até 1995.

As sucessões de cultura que apresentaram maior teor de NT, considerando a camada de $0-17,5 \mathrm{~cm}$, foram tremoço azul/milho e aveia-preta/milho, embora esta última nãotenha diferido das sucessões ervilhaca comum/milho e pousio/milho. É possível que o acúmulo de $\mathrm{N}$ na sucessão aveia preta/milho seja devido à reciclagem, favorecendo o acúmulo de $\mathrm{N}$ nas camadas mais superfíciais do solo.

O nitrogênio mineral (NM), apesar de ser uma forma muito dinâmica, apresentou, nas sucessões com ervilhaca comum e tremoço azul no inverno, as maiores quantidades na camada de $0-2,5 \mathrm{~cm}$, o mesmo verificado na profundidade de $0-17,5 \mathrm{~cm}$, em que foram 25 e $22 \%$ superiores à sucessão com pousio, respectivamente.

As sucessões pousio/milho e ervilha forrageira/ milho apresentaram os menores teores de NO, embora não tenha diferido das demais. Esse resultado é conseqüência da menor produção de matéria seca em ambas as sucessões, o queserefletiu em menor cobertura do solo. Para a sucessão pousio/ milho, a cobertura de sol o no inverno com a vegetação natural foi de $30 \%$, contra aproximadamente $90 \%$ nas leguminosas e 80\% na aveia preta (Da Ros, 1993). Esta menor cobertura do solo possivel mente tenha criado uma situação favorável à mai or decomposição da matéria orgânica na sucessão pousio/milho.

Aproximadamente, $4 \%$ do nitrogênio foi encontrado sob a forma mineral $\left(\mathrm{NO}_{3}{ }^{-}, \mathrm{NO}_{2}{ }^{-} \mathrm{eNH}_{4}{ }^{+}\right)$, à semelhança do citado por Bremner (1965), que atribui $95 \%$ do nitrogênio total do solo à sua forma orgânica. Observou-se que, após seis anos consecutivos, na sucessão tremoço azul/milho, houve um acréscimo de 126; 6 e 120 kg ha-1 de $\mathrm{N}$ total, mineral e orgânico, respectivamente, na camada de 0-17,5 cm, comparando-se com a sucessão pousio/ milho. Consi derando apenas a variação no conteúdo de nitrogênio total na camada de 0-17,5 cm, este incremento representa uma taxa anual de acúmulo diferencial de $21 \mathrm{~kg} \mathrm{ha}^{-1}$ de $\mathrm{N}$, o que é importante para a recuperação da capacidade produtiva do sol o. Todavia, isto representa apenas $20 \%$ da taxa anual de acúmulo encontrada por Bayer (1992) em Eldorado do Sul (RS), utilizando plantas que contribuíram com duas adições anuais de $\mathrm{N}$ via fixação simbiótica por leguminosas, o que justifica, em parte, a diferença encontrada. Entretanto, considerando a ausência de grandes diferenças climáticas entre as duas regiões onde se encontram os experimentos, a diferença deve-se possivel mente ao teor de argila do solo, o qual émenor no sol o deste estudo ( $15 \%$ de argila, contra $29 \%$ no Argissolo Vermelho utilizado por Bayer, 1992). A menor quantidade de argila poderia contribuir para menor proteção física de moléculas orgânicas. Segundo
Bayer (1996), essa proteçãofísica dificulta ou impede o ataque de mi crorganismos à fração orgânica euma das formas mais eficientes de proteção ocorre pela interação da matéria orgânica, principal mente com os minerais da fração argila, decorrente de suas cargas e alta área superficial específica.

\section{CONCLUSÕES}

1. A introdução de plantas de cobertura de solo, sob plantio direto, promoveu acúmul os significativos de nitrogênio mineral, orgânico e total no solo.

2. O N no solo somente foi influenciado pelas sucessões de culturas na profundidade de $0-2,5 \mathrm{~cm}$.

3. A sucessão tremoço azul/milho destacou-se pela capacidade de promover acréscimos de nitrogênio no solo, mostrando-se vantajosa em relação à sucessão aveia preta/milho.

\section{LITE RATURA CITADA}

BAYER, C. Características químicas do solo, nutrição e rendimento do milho afetados por métodos de preparo e sistemas de culturas. Porto Alegre, Universidade Federal do Rio Grande do Sul, 1992. 172p. (Tese de Mestrado)

BAYER, C. Dinâmica da matéria orgânica em sistemas de manejo de solos. Porto Alegre, UniversidadeF ederal do Rio Grande do Sul, 1996. 240p. (Tese de Doutorado)

BRASIL. Ministério da Agricultura, Departamento Nacional de Pesquisa Agropecuária, Divisão de Pesquisa Pedológica. Levantamento de reconhecimento dos sol os do Rio Grande do Sul. Recife, 1973. 431p. (Boletim, 30)

BREMNER, J .M. Total nitrogen. In: BLACK, C.A., ed. Methods of soil analysis Chemical and microbiological properties. Madison, American Society of Agronomy, 1965. p.1149-1178.

CERETTA, C.A. Fracionamento de N orgânico, substâncias húmicas e caracterização de ácidos húmicos de solo em sistemas de cultura sob plantio direto. Porto Alegre, Universidade Federal do Rio Grande do Sul, 1995. 127p. (Tese de Doutorado)

CERETTA, C.A. Adubação nitrogenada no sistema plantio direto: sucessão aveia/milho. In: CONFERÊNCIA ANUAL DE PLANTIO DIRETO, 3., Ijuí, 1998. Resumos e Palestras. Passo Fundo, Aldeia Norte, 1998. p.49-62.

DA ROS, C.O. Plantas de inverno para cobertura do solo e fornecimento de nitrogênio ao milho em plantio direto. Santa Maria, Universidade Federal de Santa Maria, 1993. 85p. (Tese de Mestrado)

DALAL, R.C. \& MAYER, R.J . Long-term trends in fertility of soils under continuous cultivation and cereal cropping in southern Queensland. I. Overall changes in soil properties and trends in winter cereal yields. Aust. J . Soil Res., 24:265279, 1986. 
EBELHAR, S.A.; FRYE, W.W. \& BLEVINS, R.L. Nitrogen from legumecover crops for no-tillagecorn. Agron. J ., 76:51-55, 1984.

FASSBENDER, M. Química de suelos com enfasis em suelos de América Latina. Turrialba, IICA, 1975. 398p.

GONCALVES, C.N. \& CERETTA, C.A. Plantas de cobertura de solo antecedendo o milho eseu efeito sobre o carbono orgânico do solo, sob plantio direto. R. Bras. Ci. Solo, 23:307-313, 1999.

LEGG, J .O.; CHICHESTER, F.W.; STANFORD, G. \& DEMAR, V.H. Incorporation of $15 \mathrm{~N}$-tagged mineral nitrogen into stable forms of soil organic nitrogen. Soil Sci. Soc. Am. Proc., 35:273-276, 1971.

PAVINATO, A. Teores de carbono e nitrogênio do solo e produtividade de milho afetados por sistemas de culturas. Porto Alegre, Universidade Federal do Rio Grande do Sul, 1993. 122p. (Tese de Mestrado)

PAVINATO, A.; AITA, C.; CERETTA, C.A. \& BEVILÁQUA, G.P. Resíduos culturais de espécies de inverno e o rendimento de grãos de milho no sistema de cultivo mínimo. Pesq. Agropec. Bras., 29:1427-1432, 1994.
SÁ, J.C.M. Nitrogênio: Transformações no solo, mobilização e imobilização. In: CURSO SOBRE MANEJ O DO SOLO NO SISTEMA PLANTIO DIRETO. Castro, Fundação ABC, 1995. p.205-212.

SANCHEZ, P.A. Soil organic matter. In: SANCHEZ, P.A., ed. Properties and management of soils in the tropics. New York, J ohn Willey \& Sons, 1976. p.162-183.

STANFORD, G.; LEGG, J.O. \& CHICHESTER, F.W. Transformation of fertilizer nitrogen in soil. I. Interpretations based on chemical extractions of labelled and unlabelled nitrogen. Plant Soil, 33:425-435, 1970.

STEVENSON, F.J . Origin and distribution of nitrogen in soil. In: STEVENSON, F.J ., ed. Nitrogen in agricultural soils. Madison, American Society of Agronomy, 1982. p.1-42.

TEDESCO, M.J .; GIANELLO, C.; BISSANI, C.A.; BOHNEN, H. \& VOLKWEISS, S.J. Análises de solo, plantas e outros materiais. Porto Alegre, Universidade Federal do Rio Grande do Sul, 1995. 174p. 